\title{
INCIDENCE AND RISK FACTORS FOR ORAL MUCOSITIS AFTER BONE MARROW TRANSPLANTATION PATIENTS UNDER LOW INTENSITY LASER THERAPY: A LONGITUDINAL STUDY
}

\author{
Cássia Emanuella Nóbrega Malta', Maria Imaculada de Queiroz Rodrigues ${ }^{1}$, José Vitor de Mota \\ Lemos $^{5}$, Natália Costa Bezerra Freire ${ }^{4}$, Fernando Barroso Duarte ${ }^{3}$, Paulo Goberlânio de Barros \\ Silva ${ }^{12,5}$, Ana Paula Negreiros Nunes Alves ${ }^{1}$
}

\begin{abstract}
1Department of Dental Clinic, Division of Oral Pathology, Faculty of Pharmacy, Dentistry and Nursing, Federal University of Ceará, Fortaleza, Ceará, Brazil. 2 Ceará Oncology School, Ceará Cancer Institute, Hospital Haroldo Juaçaba, Fortaleza, Ceará, Brazil. 3 Postdoctoral fellow at the Fred Hutchinson Cancer Research Center (Fred Hutch), Head of the Hematology, Clinical Oncology and Bone Marrow Transplant Department at the Hospital Universitário Walter Cantídio/EBSERH/UFC, responsible for the implantation of the bone marrow transplant in Ceará, Member of the editorial board of the Latin American Bone Marrow Transplantation. 4 Nurse Coordinator of the Bone Marrow Transplant Unit at the University Hospital Walter Cantídio (HUWC). 5 Post-graduate program in Dental Sciences, Unichristus, Fortaleza, Brazil.
\end{abstract}

Correspondence to: paulo_goberlanio@yahoo.com.br

\begin{abstract}
Bone marrow transplantation (BMT) has been used to treat numerous malignant and non-malignant hematological diseases, genetic and immunological diseases with a high risk of oral mucositis (OM) due to the action of antineoplastic drugs. As photobiomodulation therapy (FBMT) with low-level laser is a proven non-invasive treatment for OM, the objective of this study was to evaluate the incidence of OM in patients on BMT undergoing FBM. 53 patients undergoing treatment received FBMT (red laser, 2J, 20s, 100mW) as a preventive protocol. If OMwas observed, an infrared laser (4J, 40s, 100W) was administered. The following data were collected from patients' medical records: sex, age, chemotherapy protocol (QT) and type of BMT. An incidence of $34 \%$ was observed in the population studied ( $20 \%$ grade I, $11.3 \%$ grade II and $1.9 \%$ grade III). Prevention protocols using FBMT significantly reduced the incidence of oral mucositis $(p=0.004)$. Now, young patients with myeloid leukemia, the time between QT and BMT ( $p=0.010)$ and time of QT $(p=0.018)$ were directly associated with the increased incidence of oral mucositis. It was concluded that low-intensity preventive laser therapy was associated with a reduction in the incidence of oral mucositis, showing the importance of this therapy in the management of patients undergoing BMT.
\end{abstract}

Keywords: Hematopoietic Stem Cell Transplantation; Mucositis; Low Intensity Light Therapy

\section{INTRODUCTION}

Bone marrow transplantation (BMT), also called stem-hematopoietic cell transplantation (HSCT), is a highly complex procedure that has been used for many cases of malignant and non-malignant hematological diseases, solid neoplasms, in addition to genetic and immunological syndromes $[1,2,3]$. The HSCT modalities can be divided in three ways, when the hematopoietic stem cells come from the patient himself, called autologous; when hematopoietic stem cells can be obtained from a family donor (re- lated HSCT) or not (unrelated HSCT) it is then called an allogeneic transplant; and the syngeneic transplant, when the donor is an identical twin [3].

The most used chemotherapeutic agents in the HSCT conditioning regimens are: busulfan, cyclophosphamide, melphalan, cytarabine, carmustine, etoposide, fludarabine and carboplatin, which are grouped in different protocols depending on both the specificity and the response of neoplastic cells. $[4,5,6,7,8,9]$. 
Unlike other measure treatments, antineoplastic agents act systemically, at the cellular level, more specifically, in cells that are in the process of active cell division, interfering in the growth and division process, and they do not have a specific action, that is, they do not selectively and exclusively destroy cancer cells. In general, they are toxic to tissues of intense proliferation, characterized by high mitotic activity and short cell cycles [10,11,12]. Since they present a systemic mechanism, antineoplastic agents can have several side effects such as dysgeusia, dysphagia, dry mouth, vomiting, nausea, stomatitis and mucosal necrosis $[9,13]$.

The toxic effects caused by treatment with antineoplastic agents can have an indirect action, when toxicity occurs in bone marrow cells, leading to myelosuppression. Direct damage occurs in the mucous membranes due to the exposure of connective tissue, which may implicate the entire alimentary tract $[8,12]$. The oral cavity is a frequent target of toxic effects of chemotherapeutic agents because it presents rapid cell division tissues [13].

The rate of cell division is higher on non-keratinized oral surfaces when compared to keratinized surfaces and these differences have important implications in the tissue repair process, especially when considering the effects of antineoplastic therapy on the oral cavity. Treatments with antineoplastic agents represent a challenge to the integrity of the oral mucosa, as they limit the proliferation of epithelial cells and thus, the epithelium becomes thin and ulcerated $[14,15]$.

The most common oral alterations are: mucositis, xerostomia, bacterial infections, periodontal diseases, odontogenic infections and cavities [16]. The non-keratinized mucosa is the most affected, being the most common sites, the labial and cheek mucosa, the floor of the mouth, lateral and ventral fauces of the tongue, and the soft palate $[1,6,9,16,17]$.

Oral mucositis $(\mathrm{OM})$ is an adverse effect related to the toxicity of the antineoplastic treatment commonly observed in patients undergoing HSCT. It consists of inflammation of the oral mucosa and gastrointestinal tract, which can progress to painful ulcers, causing difficulty in chewing and swallowing, leaving the patient predisposed to secondary infection, with a significant impact on the nutritional status of the patients $[1,3,9,16,18,19]$.

As a way of avoiding treatment interruption and improving the quality of life of these patients, there are some forms of preventive treatments and therapies for OM [19]. Therefore, the goal of treating oral mucositis is to control pain, heal ulcers, recover the mucosa and the prevention of secondary infection. Therapy mainly involves oral antiseptics, corticosteroids for local use and chamomile tea washes. Additional drugs can be used for the local treatment of mucositis, such as antibacterials, antifungals and antivirals, or other drugs that stimulate the regeneration of the injured mucosa $[9,18,19]$.

In addition to these therapies, the use of low power laser or light, a photobiomodulation technique, which acts on wound repair and tissue regeneration, has been positively influencing the inflammatory and proliferative process, with an analgesic effect $[20,21,22]$. Photobiomodulation is a non-invasive treatment that involves the local application of a monochromatic, visible light source, of low intensity, density with several wavelengths, with the length of $660-730 \mathrm{~nm}$, the Red spectrum and the $880 \mathrm{~nm}$, the Infrared spectrum. When applied locally, it has potential effects on free radicals (ROSs) and / or pro-inflammatory cytokines (TNF-a, IL-6 and IL-8); which contribute to the pathogenesis of OM. Therefore, laser therapy is a method capable of preventing chemotherapy-induced OM $[16,18,19,20,23]$.

Considering that $\mathrm{OM}$ is a debilitating oral disorder and that among the therapeutic and / or preventive modalities, low-level laser is the one that presents local effect without causing systemic changes, the objective of the present study is to evaluate the incidence of OM in post-HSCT patients submitted to photobiomodulation as well as to associate this condition with risk factors.

\section{MATERIALS AND METHODS}

\section{Study Design and Analyzed Population}

This is an observational, longitudinal, prospective, quantitative study with post-bone marrow transplant patients at the Walter Cantidio Hospital (HUWC) of Federal University of Ceará, a national reference center for stem-cell transplants located in Fortaleza, capital of the State of Ceará. These patients were referred for laser therapy treatment during chemotherapy conditioning or after HSCT, since it starts 3 to 7 days before the day of the hematopoietic stem cell infusion, depending on the chemotherapy conditioning protocol. The laser therapy treatment was carried out by the team of Graduate Students in Dental Clinic (concentration in the area of Stomapatomatology) of the Dentistry Course at the Federal University of Ceará (UFC), linked to the Oral Laser extension project. 


\section{Inclusion, Exclusion and Withdrawal Criteria}

Individuals of both sexes and aged 13 years or over were included. Participants were mandatorily admitted to the HUWC to perform HSCT and received a preventive and / or therapeutic protocol for oral mucositis with laser therapy in the period from November 2018 to September 2019.

Patients that for some reason interrupted prophylactic or therapeutic treatment with laser therapy during HSCT were excluded from the study. Patients who died before beginning laser therapy sessions or who evolved with complications and needed orotracheal intubation were removed from the study.

\section{Sample Calculation}

Based on the study by Valeh et al., (2018) [24] who observed that the time of oral mucositis in patients who undergo bone marrow transplantation differs significantly between different types of treatment (multiple myeloma: $8.6 \pm 3.3$ days; leukemia: $10.9 \pm$ 3.2 days), it is estimated to be necessary to evaluate 42 patients in order to obtain a sample that represents the incidence of oral mucositis in patients after bone marrow transplantation, adopting a $90 \%$ power and a $95 \%$ confidence spectrum. In view of the possibility of sample loss during the study, $25 \%$ was added to this study, totalizing 53 Patients Evaluated Longitudinally.

\section{Pre, Trans and Post Hsct Oral Care}

During the hospitalization period, when starting the conditioning process with high doses of chemotherapy, which varied according to the service protocol based on the disease to be treated, the patients were followed up by the HUWC nursing team and, if they evolved with oral mucositis, the therapeutic protocol with laser therapy was initiated. Upon reaching D-2 (three days for HSCT to be performed), the prevention protocol with laser therapy was instituted and lasted until D + 12 (twelve days after the transplant). However, if it evolved to OM, the therapeutic protocol of laser therapy was implemented and extended until the complete involution of OM.

As part of the pre-HSCT protocol, every patient is referred for dental evaluation prior to admission and is accompanied by the HUWC Dental Surgeon, in which the condition of mucous membranes, teeth (presence of cavities, periodontal disease) and jaw are evaluated. All necessary dental intervention is performed prior to transplantation, aiming to reduce risks during treatment.

Patients are advised on oral hygiene care during their hospital stay.

\section{Chemotherapy Protocol}

Conditioning for HSCT starts 3 to 7 days before the day of hematopoietic stem cell infusion, depending on the chemotherapy protocol. Negative days are considered before the day of the stem cell infusion (D-7; D-1). The day of the infusion is considered the zero day (D-0). From the day of the infusion, the time count in post-transplant days is positive $(D+1, D+3$, D+7) $[7,8]$.

Patients were admitted to receive the conditioning regimen with high doses of chemotherapy varying with the disease and its service protocol. The allogeneic related myeloablative conditioning is done with BuFlu (Busulfan $0.8 \mathrm{mg} / \mathrm{kg}$ and Fludarabine 30 $\mathrm{mg} / \mathrm{m}^{2}$ ), starting at D-7 until D-3 and at $D+1$, the patient receives the infusion of four doses of Metrotexate $10 \mathrm{mg} / \mathrm{m}^{2}$. The haploidentical conditioning occurs with BuFluCy (Busulfan $110 \mathrm{mg} / \mathrm{m}^{2}$ and Fludarabine $25 \mathrm{mg} / \mathrm{m}^{2}$ ), from D-7 to D-4, followed by Fludarabine $25 \mathrm{mg} / \mathrm{m}^{2}$, Cyclophosphamide 14.5 $\mathrm{mg} / \mathrm{kg}$ and Mesna 0.4 and with a concentration of 8 on D-3 and D-2. After infusion of hematopoietic stem cells (HSC), a new dose of Cyclophosphamide $50 \mathrm{mg} / \mathrm{kg}$ and Mesna 0.4 and 8 are administered, on $\mathrm{D}+3$ and $\mathrm{D}+4$. The related allogeneic conditioning of myeloablative is done with FluMel 180, started on D-6 through D-4 with Fludarabine $30 \mathrm{mg} / \mathrm{m}^{2}$, followed with Fludarabine $30 \mathrm{mg} / \mathrm{m}^{2}$ and Melfalan $90 \mathrm{mg} / \mathrm{m}^{2}$ until D-2. After HSC infusion, a new conditioning is performed with Metrotexate $10 \mathrm{mg} / \mathrm{m}^{2}$. Regarding the allogeneic conditioning of Aplastic Anemia, FluCyATG is used, which is initiated on D-6 with Fludarabine $30 \mathrm{mg} / \mathrm{m}^{2}$, Cyclophosphamide 30 $\mathrm{mg} / \mathrm{m}^{2}$, Mesna $30 \mathrm{mg} / \mathrm{kg}$ and on D-4, antithymocytic globulin is added ( ATG) of rabbit with $2.5 \mathrm{mg}$ / $\mathrm{kg}$ until D-2. After HSCT, the patient receives new chemotherapy doses with Metrotexate $15 \mathrm{mg} / \mathrm{m}^{2}$ on $D+1, D+3, D+6$ and $D+11$. The Myeloblative conditioning for Promyelocytic is the CyBu, composed of Cyclophosphamide $60 \mathrm{mg} / \mathrm{kg}$, Mesna $30 \mathrm{mg} / \mathrm{kg}$ at hour 0 , followed by Mesna $15 \mathrm{mg} / \mathrm{kg}$ at hour 4 and 8 , on days D-7 and D-6. On days D-5 to D-2 is done the conditioning with Busulfan $0.8 \mathrm{mg} / \mathrm{kg}$.

The chemotherapy protocol called LACE, used for lymphoma cases, consists of Lomustine $200 \mathrm{mg} / \mathrm{m}^{2}$, Etoposide $1000 \mathrm{mg} / \mathrm{m}^{2}$ and Cytarabine $2000 \mathrm{mg} /$ $\mathrm{m}^{2}$ and it is implemented from D-7 to D-5, however from D-4 up to D-2 it is done the conditioning with Cyclophosphamide $1800 \mathrm{mg} / \mathrm{m}^{2}$ with Mesna 1800 $\mathrm{mg} / \mathrm{m}^{2}$.

The protocols with Melfalano of $200 \mathrm{mg} / \mathrm{m}^{2}$ or Melfalano of $100 \mathrm{mg} / \mathrm{m}^{2}$ are performed for the conditioning of Multiple Myeloma. 


\section{Application of Low Intensity Laser Therapy}

The prophylactic application of the laser was initiated depending on the referral of the nursing team to the Oral Laser extension project team. Usually, patients were referred during chemotherapy conditioning between D-3 to D0 (HSCT day) or up to three days after transplantation ( $D+3)$. In addition, patients with $\mathrm{OM}$ in the oral cavity received the therapeutic laser therapy protocol.

For the application of laser therapy, the low-power laser THERAPY XT (DMC, São Carlos, SP, Brazil) with a wavelength of $\lambda 660 \mathrm{~nm}$ (Red laser) and $808 \mathrm{~nm}$ (Infrared laser) was used, with a fixed power of $100 \mathrm{~mW}$. The protocol used for red light $(V)(\lambda 660 \mathrm{~nm})$ was the point and contact application, perpendicular to the oral mucosa, with energy of $2 \mathrm{~J}, 20$ seconds per point, energy density $71.42 \mathrm{~J} / \mathrm{cm} 2$, calculated for the device used with a spot size of $0.028 \mathrm{~cm}^{2}$. On the other hand, for the infrared (IV) laser ( $\lambda 808 \mathrm{~nm})$, at the same power $(100 \mathrm{~mW}), 4 \mathrm{~J}, 40$ seconds per point, with an energy density of $142.85 \mathrm{~J} / \mathrm{cm} 2$, calculated for the device with size spot of $0.028 \mathrm{~cm} 2$, at the site of the lesions, one point for each $0.25 \mathrm{~cm} 2$ of area.

The point applications of the preventive protocol started with $2 \mathrm{~J}, \mathrm{~V}$, being performed in buccal mucosa (bilateral) with three points, lateral border of tongue (bilateral) with five points, floor region with three points and palate region with three points (Figure 1). For the therapeutic protocol, the punctual technique was performed with 4J, IV covering the entire length of the lesion.

The application in oropharynx was performed in patients with painful symptoms when swallowing, with the therapeutic protocol with $4 \mathrm{~J}$, IV in the punctual technique, with 4 points running through the oropharynx (bilateral).

\section{Statistical Analysis}

The data were tabulated in Microsoft Excel and exported to the Statistical Packcage for the Social Sciences (SPSS) version 20.0 for Windows software, in which the analysis was performed adopting a $95 \%$ confidence.

The absolute and percentage frequencies of clinical and therapeutic variables were calculated and for the age and the periods between QT, the mean and standard deviation were calculated. To assess risk factors, oral mucositis in HSCT patients undergoing PBMT, categorical data were subjected to Fisher's exact test or Pearson's chi-square test and quantitative data to the Kolmogorov-Smirnov normality test and the $t$ test of Student (parametric data).

\section{Ethical Aspects}

The study was approved by the Ethics and Research Committee with Human Beings of the Federal University of Ceará (UFC) and of HUWC with protocol number CAAE 36765514.1.0000.5045 and it was started after the approval and signature of the informed consent form by each patient that was included in the study.

\section{RESULTS}

Characterization of the sample of HSCT patients undergoing PBMT

The sample consisted of 53 patients, of whom the majority $(n=31,58.5 \%)$ were female and the average age was $43.9 \pm 15.3$, ranging between 13 and 72 years. The most prevalent base disease was Multiple Myeloma with 17 (32.1\%) cases. The most used chemotherapy protocol was LACE $(\mathrm{n}=12,22.6 \%)$, followed by BUFLU $(n=11,20.8 \%)$ and melphalan $(n=$ $10,18.9 \%)$. Among the different types of bone marrow transplantation (HSCT), the most prevalent was autologous, represented by 31 (58.5\%) patients, the mean time between QT and HSCT was $5.7 \pm 2.6$ days. Patients spent an average of $4.5 \pm 2.2$ days on QT and all underwent PBMT.

The average number of days of application of PBMT was $10.6 \pm 5.9$ days ranging from three to 28 days of application of PBMT. The incidence of oral mucositis was $34 \%(n=18)$, with most patients presenting grade 1 ( $n=11,20.8 \%)$, followed by grade $2(n=6$, $11.3 \%$ ) and only one patient (1.9\%) presented grade 3 mucositis (Table 1; Figure 2).

Risk factors associated with oral mucositis in HSCT patients undergoing PBMT

There was no significant difference in the incidence of oral mucositis by sex $(p=0.876)$, but the patients who presented mucositis had a significantly lower average age than the patients who did not present it $(p=0.013)$. The base diseases most strongly associated with oral mucositis were chronic myeloid leukemia and acute myeloid leukemia $(p=0.010)$ and the chemotherapy regimens was BUFLU $(p=0.005)$. The type of HSCT did not significantly influence the incidence of oral mucositis (Table 2).

The most used type of PBMT was the protocol with Laser V, 2J, 20sec and the use of Laser IV, 4J, 40sec was directly associated with mucositis $(p=0.048)$. Prevention protocols significantly reduced the incidence of oral mucositis $(p=0.004)$ and the time between QT and HSCT $(p=0.010)$ and QT time $(p=$ 
0.018) were directly associated with an increased incidence of oral mucositis. As a result, patients who developed mucositis had a longer PBMT time than patients who did not develop it $(p=0.039)$ (Table 3). The patient who presented grade 3 mucositis required 28 sessions of PBMT (Figure 3).

The need for post-prevention treatment was significantly less in patients who did not develop oral mucositis ( $p<0.001)$ as well as treatment in the oropharynx ( $p<0.001)$. Oral mucositis was not associated with the incidence of deaths $(p=1,000)$ or with the number of HSCT $(p=0.598)$ (Table 3$)$.

\section{DISCUSSION}

In the present study, most patients (66\%) did not develop mucositis. A similar result was observed in another study, with patients undergoing HSCT and who received preventive laser therapy, where $66.7 \%$ of the patients did not present mucositis [21]. It is added that, in another study, Silva et al., (2014) [25], observed that $72.8 \%$ of patients on preventive laser therapy protocol also did not developed the condition. It is emphasized that, among the patients evaluated in the present study who presented mucositis, most were classified in grade 1 , where there is no ulcer, as observed in the works by Silva et al., (2015) [26] and Bezinelli et al., (2015) [3], who evaluated patients under a preventive protocol.

The appearance of mucositis was associated with younger patients, with data corroborated by other studies $[27,28]$. On the other hand, Vagliano et al., (2011) [27] stated that the incidence and severity of oral mucositis is more associated with the type of transplant and conditioning regime, than the patient's age, since the conditioning can be more or less toxic to the oral mucosa. However, in the present study, the type of HSCT was not related to the incidence of mucositis in patients.

Leukemia was the disease most associated with the appearance of oral mucositis, as described by other authors, where this disease was associated with a higher incidence of the lesion, in addition to greater severity [28]. However, the same authors believe that this finding is much more directly related to the conditioning regime used for patients than any other factor. In the present study, the chemotherapy protocol used to treat leukemia was BUFLU, in which the association of these protocols with extreme toxicity has been described in the literature, especially in tissues with rapid cell division, such as the oral cavity $[9,19]$.
The most used preventive protocol was Laser V, 2J, $20 \mathrm{sec}$, although the protocols are quite variable in the literature, which is a major limitation for the establishment of an effective standard protocol for the prevention of oral mucositis. Even so, there is a certain standardization for the use of red spectrum laser for prevention $[23,26,29,30]$.

In the present study, the preventive protocol was effective in reducing the incidence of mucositis, and this result is well described in the literature [21,29,30], evidencing the preventive potential of laser therapy for oral mucositis in patients undergoing HSCT. The mechanisms by which laser therapy helps prevent oral mucositis are not yet fully elucidated but are better understood today. These are mainly associated, among others, with the stimulation of greater ATP production by the cell, increased production of growth factors, increased proliferation and differentiation rates, in addition to important factors for healing [32].

The time between QT and HSCT and QT time were associated with an increased incidence of mucositis. These data are in agreement with the literature where it has already been described that due to longer exposure time of the oral cavity to conditioning drugs, associated with their toxicity, time is a triggering factor for oral mucositis [27].

Among the patients who developed mucositis, there was a need for post-prevention treatment. Associated with this result, patients who did not develop the lesion required less time for post-prevention treatment, as well as treatment in the oropharynx. These findings are related to the fact that once the lesion arises, the use of the laser is maintained daily until it is fully healed [29,33], this time can be extended for several days, as in the case of one of the patients of the current research that required 28 daily sessions for the healing of the mucosa. In patients who do not develop the lesion, the preventive protocol has a more limited number of days $[9,19,29,31,33,34]$.

\section{CONCLUSION}

Low-level preventive laser therapy was associated with a reduction in the incidence of oral mucositis, showing the importance of this therapy in the management of patients undergoing HSCT. The main risk factors for the development of oral mucositis in the population studied were age (young patients), the conditioning regime (BLUFLU) and base disease (myeloid leukemia). 


\section{REFERENCES:}

1. Woo SB. A longitudinal study of oral ulcerative mucositis in bone marrow tranplant patients. Cancer. 1993v.72, n.5, p.1612-1617.

2. Vokurka S, Steinerova K, Karas M, Koza V. Characteristics and risk factors of oral mucositis after allogeneic stem cell transplantation with FLU/ MEL conditioning regimen in context with $\mathrm{BU} /$ CY2. Bone Marrow Transplant. 2009v.44,n.9,p. 601-605.

3. Bezinelli LM, de Paula EF, da Graça LRM et al. Cost-effectiveness of the introduction of specialized oral care with laser therapy in hematopoietic stem cell transplantation. Hematol Oncol. 2014 v.32, n.1, p. 31-39.

4. Cutler C, Li S, Kim HT, et al. Mucositis after allogeneic hematopoietic stem cell transplantation: a cohort study of methotrexate- and non-methotrexate-containing graft-versus-host disease prophylaxis regimens. Biol Blood Marrow Transplant. 2005 v.11, n. 5, p. 383-388.

5. Barrach RH, Souza MP, Silva DPC, Lopez PS et al. Oral changes in individuals undergoing hematopoietic stem cell transplantions. Braz J. Otorhinolaryngol. 2015 v.81, n.1,p. 141-147.

6. Al-Taie A, Al-Shohani AD, Albasry Z et al. Current topical trends and novel therapeutic approaches and delivery systems for oral mucositis manegement. Journal of Pharmacy e BioAllied Sciences. 2020 v. 12, n.2, p. 94-101.

7. Castro CGJ, Gregianin LJ, Brunetto AL. Transplante de medula óssea e transplante de sangue de cordão umbilical em pediatria. Journal Pediatric,2001 v.77, n. 5, 345-360.

8. Chaudhry HM, Bruce AJ, Wolf RC, et al. The Incidence and severity of oral mucositis among allogeneic hematopoietic stem cell transplantation patients: a systematic review. Biol Blood Marrow Transplant. 2016 v.77, n. 5, 605-616.

9. Peng J, Shi Y, Wang J, Wang F et al. Low-level laser therapy ini the preventio and treatment of oral mucositis: a systematic review and meta-analysis. Oral Surgery, Oral Medicine, Oral Pathology and Oral Radiology. 2020.

10. Bensadoun RJ, Nair RG. Low-level laser therapy in the prevention and treatment of cancer therapy-induced mucositis: 2012 state of the art based on literature review and meta-analysis. Curr Opin Oncol 2012 v.24, p. 363-70.
11. López BC. Oral toxicity produced by chemotherapy: A systematic review. J Clin Exp Dent, 2018 v.6, n.1, p. 80-90.

12. Shapiro CL, Recht A. Drug Therapy: side effects of adjuvante treatment of breast câncer. Breast Cancer Research and treatment. 2017;62(2):141-150

13. Chen YC, Hunter DJ. Molecular epidemiology of câncer. Cancer Journal of Clinic 2015 v.55, n.1, p. 45-54.

14. Antunes HS, Herchenhorn D, Small IA, et al. Phase III trial of low-level laser therapy to prevent oral mucositis in head and neck cancer patients treated with concurrent chemoradiation. v.109, p. 2013 v.109, p. 297-302.

15. Sonis ST, Oster G, Fuchs $H$, et al. Oral mucositis and the clinical and economic outcomes of hematopoietic stem-cell transplantation. J Clin Oncol. 2001 v.19, n.8, p. 2201-2205.

16. Cronshaw M, Parker S, Anagnostaki E, Mylona $V$, et al.. Photobiomodulation and Oral Mucositis: A systematic review. Dentistry Journal, 2020 v.8,n.3,p. 87.

17. Migliorati C, Hewson I, Lalla RV, et al.. Systematic review of laser and other light therapy for the management of oral mucositis in cancer patients. Study Group of the Multinational Association of Supportive Care in Cancer/International Society of Oral Oncology (MASCC/ISOO). Support Care Cancer 2013 v.21, p. 333-41.

18. Van Leeuwen S, Potting C, Huysmans M-C, Blijlevens N. Salivary changes before and after hematopoietic stem cell transplantation: a systematic review. Biol Blood Marrow Transplant. 2019 v.25, n.6, p. 1055-1061.

19. Sant AG, Normando AGC, Toledo I et al. Topical treatment of oral mucositis in câncer patients: $\mathrm{A}$ systematic review of randomized clinical trials. Asian Pac J Cancer Prev. 2020 v. 21, n.7,p. 1851-1866.

20. Shouval R, Eshel A, Dubovski B, Kuperman AA et al. Patterns of salivar microbiota injury and oral mucositis in recipientes of allogeneic hematopoietic stem cell transplantation. 2020 v.4, n.3, p. 2912-2917.

21. Silva GBL, Mendonça EF, Bariani C, Antunes HS, Silva MAG. The Prevention of Induced Oral Mucositis with Low-Level Laser Therapy in Bone Marrow Transplantation Patients: a randomized 
clinical trial. Photomedicine And Laser Surgery. 2011 v.29, n.1, p. 27-31.

22. Bjordal JM, Bensadoun RJ, Tunèr J, Frigo L, Gjerde K, Lopes-Martins RA. A systematic review with meta-analysis of the effect of low-level laser therapy (LLLT) in cancer therapy-induced oral mucositis. Support Care Cancer 2011 v.19, p. 1069-77.

23. Bezinelli LM, Eduardo FP, Neves VD et al. Quality of life related to oral mucositis od patients undergoing haematopoietic stem cell transplantation and receiving specialised oral care with low-level laser therapy: a prospective observation study. 2016 v.25, n.4, p. 668-674.

24. Lalla RV, Bowen J, Barasch A, et al. Mucositis Guidelines Leadership Group of the Multinational Association of Supportive Care in Cancer and International Society of Oral Oncology (MASCC/ ISOO), MASCC/ISOO clinical practice guidelines for the management of mucositis secondary to cancer therapy. Cancer 2014 v. 120, p. 1453-61.

25. Silva GBL, Sacono NT, Othon-Leite AF, Mendonça EF, Arantes AM, Bariani C, et al. Effect of low-level laser therapy on inflammatory mediator release during chemotherapy-induced oral mucositis: a randomized preliminary study. Lasers In Medical Science. 2014 v.30. n.1, p. 117-126.

26. Silva LC, Sacono NT, Freire MCM, Costa LR, Batista AC, Silva GBL. The Impact of Low-Level Laser Therapy on Oral Mucositis and Quality of Life in Patients Undergoing Hematopoietic Stem Cell Transplantation Using the Oral Health Impact Profile and the Functional Assessment of Cancer Therapy-Bone Marrow Transplantation Questionnaires. Photomedicine And Laser Surgery. 2015 v.33, n.7, p. 357-363.

27. Vagliano L, Feraut C, Gobetto G, Trunfio A, Errico A, Campani V, et al. Incidence and severity of oral mucositis in patients undergoing haematopoietic SCT_results of a multicentre study. Bone Marrow Transplantation. 2010 v.46, n.5, p. 727-732.
28. Valeh M, Kargar M, Mansouri A, Kamranzadeh $H$, Gholami K, Heidari K, et al. Factors Affecting the Incidence and Severity of Oral Mucositis Following Hematopoietic Stem Cell Transplantation. International Journal of Hematology-Oncology and Stem Cell Research. 2018 v.12,n.2, p. 142-152.

29. Ferreira B, Silveira FMM, Orange FA. Low-level laser therapy prevents severe oral mucositis in patients submitted to hematopoietic stem cell transplantation: a randomized clinical trial. Supportive Care In Cancer. 2015 v.24, n.3, p. 1035-1042.

30. Zadik Y, Arany PR, Fregnani ER, Bossi P, Antunes $\mathrm{HS}$; Bensadoun RJ, et al. Systematic review of photobiomodulation for the management of oral mucositis in cancer patients and clinical practice guidelines. Supportive Care In Cancer. 2019 v.27, n. 10,p. 3969-3983.

31. Salvador DRN, Soave DF, Sacono NT, Castro EF, Silva GBL, Silva LP, et al. Effect of photobiomodulation therapy on reducing the chemo-induced oral mucositis severity and on salivary levels of CXCL8/interleukin 8, nitrite, and myeloperoxidase in patients undergoing hematopoietic stem cell transplantation: a randomized clinical trial. Lasers In Medical Science. 2017 v.32, n.8, p. 1801-1810.

32. Marques ECP, Lopes FP, Nascimento IC, Morelli J, Pereira MV, Meiken VMM, et al. Photobiomodulation and photodynamic therapy for the treatment of oral mucositis in patients with cancer. Photodiagnosis And Photodynamic Therapy. 2020 v. 29, p. 101621.

33. Eduardo FP, Bezinelli L, Luiz AC, Correa L, Vogel C, Eduardo CP. Severity of Oral Mucositis in Patients Undergoing Hematopoietic Cell Transplantation and an Oral Laser Phototherapy Protocol: a survey of 30 patients. Photomedicine And Laser Surgery. 2009 v.21, n.1, p. 137-144.

34. Jaguar GC, Prado JD, Nishimoto IN, Pinheiro MC, Castro DO, Perez DC, et al. Low-energy laser therapy for prevention of oral mucositis in hematopoietic stem cell transplantation. Oral Diseases. 2017 v.13, n.6. p. 538-543. 
FIGURE 1 - Schematic drawing of the application of preventive protocols of PBMT in the oral cavity of patients undergoing HSCT.

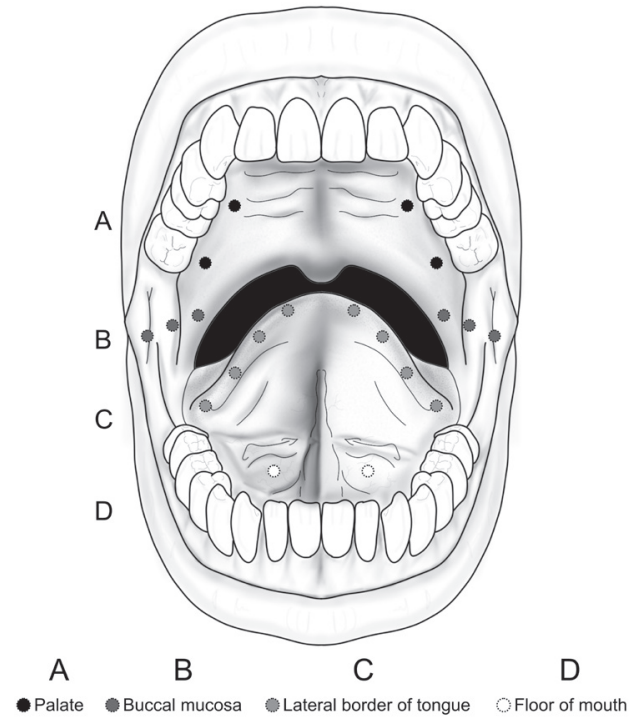

FIGURE 2 - Representation of degrees of oral mucositis (1, 2, 3 and 4) in post-HSCT patients undergoing PBMT in the oral cavity.

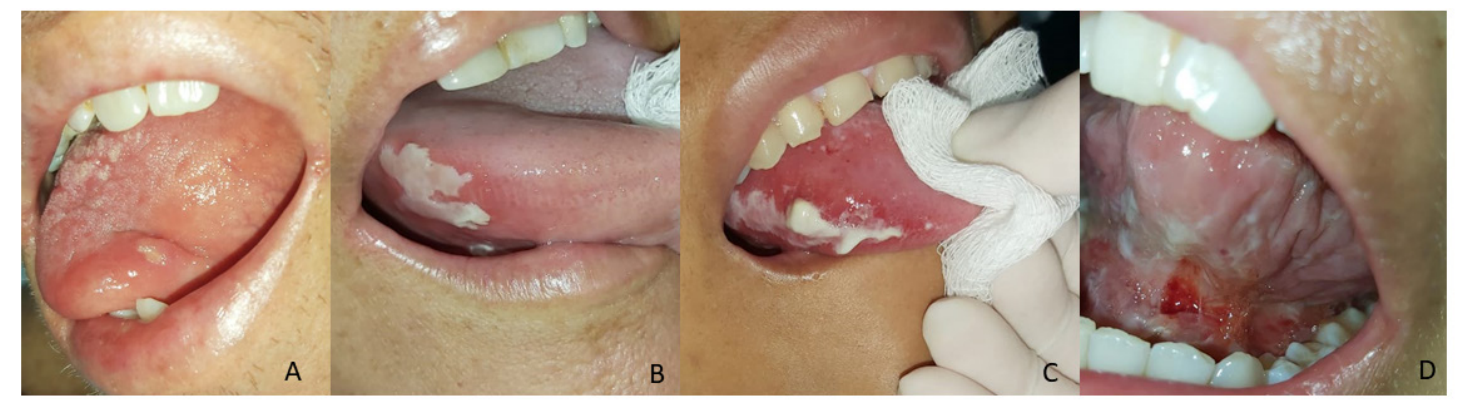

Classification of Oral Mucositis according to WHO: 1 (A), 2 (B), 3 (C), 4 (D) - personal archive photos

\section{DEGREES OF MUCOSITE}

\begin{tabular}{|c|c|c|c|c|c|}
\hline ESCALA & 0 & 1 & 3 & 4 \\
\hline $\begin{array}{c}\text { Oral Mucositis } \\
\text { Toxicity (WHO) }\end{array}$ & No changes & $\begin{array}{c}\text { Sensitivity and } \\
\text { erythema }\end{array}$ & $\begin{array}{c}\text { Erythema, Ulcer, } \\
\text { possible to swallow }\end{array}$ & $\begin{array}{c}\text { Ulcer, extensive } \\
\text { erythema, difficulty } \\
\text { swallowing }\end{array}$ & $\begin{array}{c}\text { Ulcer, bleeding, } \\
\text { extensive lesion and } \\
\text { unable to swallow }\end{array}$ \\
\hline
\end{tabular}

GRAPHIC 3 - Mean and standard deviation of the number of PBMT sessions of patients who did not develop and patients who developed grade 1, 2 and 3 oral mucositis undergoing PBMT.

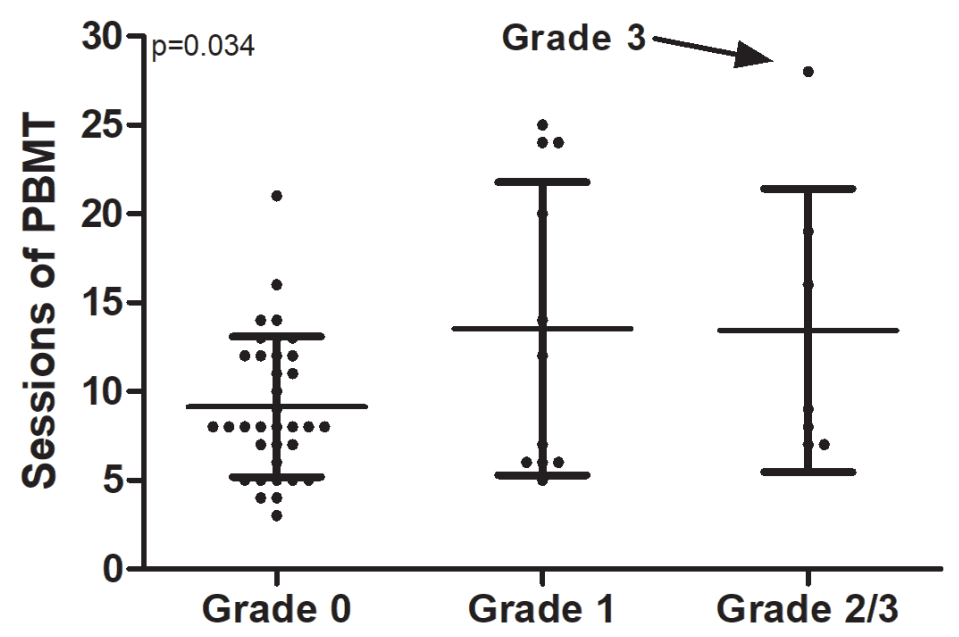


TABLE 1- Clinical and therapeutic profile of patients undergoing bone marrow transplantation and PBMT for prevention and treatment of oral mucositis

\begin{tabular}{|c|c|}
\hline TOTAL & $53(100.0 \%)$ \\
\hline \multicolumn{2}{|l|}{ Gender } \\
\hline Masculine & 22 (41.5\%) \\
\hline Feminine & 31 (58.5\%) \\
\hline Age & $43.9 \pm 15.3(13-72)$ \\
\hline \multicolumn{2}{|l|}{ Base disease } \\
\hline Dendritic Leukemia cell I & $1(1.9 \%)$ \\
\hline Chronic myeloid leukemia & $6(11.3 \%)$ \\
\hline Multiple Myeloma & $17(32.1 \%)$ \\
\hline Acute Myeloid Leukemia & $8(15.1 \%)$ \\
\hline Follicular T Lymphoma & $1(1.9 \%)$ \\
\hline LCM - Mantle Cell Lymphoma & $5(9.4 \%)$ \\
\hline Hodgkin's lymphoma & $6(11.3 \%)$ \\
\hline Aplastic Anemia & $3(5.7 \%)$ \\
\hline Acute Lymphocytic Leukemia & $5(9.4 \%)$ \\
\hline Germ Cell Tumor & $1(1.9 \%)$ \\
\hline \multicolumn{2}{|l|}{ QT Protocol } \\
\hline BUFLU & $11(20.8 \%)$ \\
\hline MELPHALAN 100 & $7(13.2 \%)$ \\
\hline BUFLUCY & $3(5.7 \%)$ \\
\hline LACE & $12(22.6 \%)$ \\
\hline BUFLUATG & $3(5.7 \%)$ \\
\hline FLU MEL & $2(3.8 \%)$ \\
\hline MELPHALAN 200 & $10(18.9 \%)$ \\
\hline FLUCYATG & $4(7.5 \%)$ \\
\hline CYBU & $1(1.9 \%)$ \\
\hline \multicolumn{2}{|l|}{ TCTH type } \\
\hline Allogeneic & $14(26.4 \%)$ \\
\hline Autologous & $31(58.5 \%)$ \\
\hline Haplo & $3(5.7 \%)$ \\
\hline NAP & $5(9.4 \%)$ \\
\hline Time between QT and TCTH & $5.7 \pm 2.6(2-16)$ \\
\hline QT Time & $4.5 \pm 2.2(1-19)$ \\
\hline Days in LLLT & $10.6 \pm 5.9(3-28)$ \\
\hline \multicolumn{2}{|l|}{ Mucositis Grade } \\
\hline 0 & $35(66.0 \%)$ \\
\hline 1 & $11(20.8 \%)$ \\
\hline 2 & $6(11.3 \%)$ \\
\hline 3 & 1 (1.9\%) \\
\hline
\end{tabular}

Data expressed as absolute frequency and percentage or average \pm SD (minimum - maximum).

QT - Chemotherapy; BuFlu - Bulsufan and Fludarabine; BuFluCy - Bulsufan, Fludarabine and Cyclophosphamide; FluMel - Fludarabine and Melphalan; FluCyATG - Fludarabine, cyclophosphamide and rabbit ATG; CyBu - Cyclophosphamide and Mesna; LACE - Lomustine, Etoposide and Cytarabine; TCTH - Stem-Hematopoietic Cell Transplantation ; LLLT - Low Level Laser Therapy.

Patients submitted to HSCT at Walter Cantidio Hospital of Federal University of Ceará- Fortaleza-CE. 
TABLE 2 - Influence of the clinical and therapeutic profile of patients undergoing bone marrow transplantation and PBMT on the incidence of oral mucositis

\begin{tabular}{|c|c|c|c|}
\hline & \multicolumn{2}{|c|}{ MUCOSITIS GRADE } & \multirow[b]{2}{*}{ P-VALUE } \\
\hline & NO & YES & \\
\hline \multicolumn{4}{|l|}{ Gender } \\
\hline Masculine & $14(40.0 \%)$ & $8(44.4 \%)$ & $0,756^{a}$ \\
\hline Feminine & $21(60.0 \%)$ & $10(55.6 \%)$ & \\
\hline Age & $47.6 \pm 15.0$ & $36.7 \pm 13.8$ & $0,013^{b}$ \\
\hline \multicolumn{4}{|l|}{ Base disease } \\
\hline Dendritic leukemia cells & $0(0.0 \%)$ & $1(5.6 \%)$ & $0,010^{a}$ \\
\hline Chronic myeloid leukemia & $2(5.7 \%)$ & $4(22.2 \%)^{*}$ & \\
\hline Multiple Myeloma & $15(42.9 \%)^{*}$ & $2(11.1 \%)$ & \\
\hline Acute Myeloid Leukemia & $3(8.6 \%)$ & $5(27.8 \%)^{*}$ & \\
\hline Follicular T Lymphoma & $0(0.0 \%)$ & $1(5.6 \%)$ & \\
\hline $\begin{array}{c}\text { LCM - Mantle Cell } \\
\text { Lymphoma }\end{array}$ & $5(14.3 \%)^{*}$ & $0(0.0 \%)$ & \\
\hline Hodgkin's lymphoma & $5(14.3 \%)^{*}$ & $1(5.6 \%)$ & \\
\hline Aplastic Anemia & $3(8.6 \%)^{*}$ & $0(0.0 \%)$ & \\
\hline $\begin{array}{c}\text { Acute Lymphocytic } \\
\text { Leukemia }\end{array}$ & $2(5.7 \%)$ & $3(16.7 \%)$ & \\
\hline Germ Cell Tumor & $0(0.0 \%)$ & $1(5.6 \%)$ & \\
\hline \multicolumn{4}{|l|}{ QT Protocol } \\
\hline BUFLU & $4(11.4 \%)$ & $7(38.9 \%)^{*}$ & $0,005^{b}$ \\
\hline MELPHALAN 100 & $5(14.3 \%)$ & $2(11.1 \%)$ & \\
\hline BUFLUCY & $1(2.9 \%)$ & $2(11.1 \%)$ & \\
\hline LACE & $10(28.6 \%)^{*}$ & $2(11.1 \%)$ & \\
\hline BUFLUATG & $1(2.9 \%)$ & $2(11.1 \%)$ & \\
\hline FLU MEL & $0(0.0 \%)$ & $2(11.1 \%)$ & \\
\hline MELPHALAN 200 & $10(28.6 \%)^{*}$ & $0(0.0 \%)$ & \\
\hline FLUCYATG & $4(11.4 \%)^{*}$ & $0(0.0 \%)$ & \\
\hline CYBU & $0(0.0 \%)$ & $1(5.6 \%)$ & \\
\hline \multicolumn{4}{|l|}{ TCTH type } \\
\hline Allogeneic & $7(20.0 \%)$ & $7(38.9 \%)$ & $0,058^{a}$ \\
\hline Autologous & 25 (71.4\%) & $6(33.3 \%)$ & \\
\hline Haplo & $1(2.9 \%)$ & $2(11.1 \%)$ & \\
\hline NAP & $2(5.7 \%)$ & $3(16.7 \%)$ & \\
\hline
\end{tabular}

${ }^{*} p<0,05$, aFisher's exact test or Pearson's chi-square test ( $\left.n, \%\right)$; $b$ Student's t test (mean \pm SD).

QT - Chemotherapy; BuFlu - Bulsufan and Fludarabine; BuFluCy - Bulsufan, Fludarabine and Cyclophosphamide; FluMel - Fludarabine and Melphalan; FluCyATG - Fludarabine, cyclophosphamide and rabbit ATG; CyBu - Cyclophosphamide and Mesna; LACE - Lomustine, Etoposide and Cytarabine; TCTH -Hematopoietic Stem Cell Transplantation

Patients submitted to HSCT at Walter Cantidio Hospital of Federal University of Ceará- Fortaleza-CE. 
TABLE 3 - Influence of the PBMT protocol on the incidence of oral mucositis in patients with HSCT

\begin{tabular}{|c|c|c|c|}
\hline & \multicolumn{2}{|c|}{ MUCOSITIS GRADE } & \multirow[b]{2}{*}{ P-VALUE } \\
\hline & NO & YES & \\
\hline \multicolumn{4}{|l|}{ Laser type } \\
\hline Laser V, 2J, 20seg & $32(91.4 \%)^{*}$ & $12(66.7 \%)$ & $0,048^{a}$ \\
\hline Laser IV, 4J, 40seg & $3(8.6 \%)$ & $6(33.3 \%)^{*}$ & \\
\hline \multicolumn{4}{|l|}{ LLLT Intent } \\
\hline Treatment & $1(2.9 \%)$ & $6(33.3 \%)^{*}$ & $0,004^{a}$ \\
\hline Prevention & $34(97.1 \%)^{*}$ & $12(66.7 \%)$ & \\
\hline Time between QT and TCTH (Days) & $5.1 \pm 2.2$ & $7.0 \pm 2.8$ & $0,010^{a}$ \\
\hline QT Time (Days) & $4.03 \pm 2.3$ & $5.6 \pm 1.8$ & $0,018^{b}$ \\
\hline LLLT Time (Days) & $9.1 \pm 3.9$ & $13.5 \pm 7.9$ & $0,039^{b}$ \\
\hline \multicolumn{4}{|l|}{ Post-prevention treatment } \\
\hline No & $34(97.1 \%)^{*}$ & $5(27.8 \%)$ & $<0,001^{a}$ \\
\hline Yes & $1(2.9 \%)$ & $13(72.2 \%)^{*}$ & \\
\hline \multicolumn{4}{|l|}{ Oropharynx treatment } \\
\hline No & $34(97.1 \%)^{*}$ & $8(44.4 \%)$ & $<0,001^{a}$ \\
\hline Yes & $1(2.9 \%)$ & $10(55.6 \%)^{*}$ & \\
\hline \multicolumn{4}{|l|}{ Death } \\
\hline No & $32(91.4 \%)$ & $16(88.9 \%)$ & 1,000 \\
\hline Yes & $3(8.6 \%)$ & $2(11.1 \%)$ & \\
\hline \multicolumn{4}{|l|}{ TCTH Quantity } \\
\hline 1 & $33(94.3 \%)$ & $16(88.9 \%)$ & 0,598 \\
\hline 2 & $2(5.7 \%)$ & $2(11.1 \%)$ & \\
\hline
\end{tabular}

${ }^{*} \mathrm{p}<0,05$, aFisher's exact test or Pearson's chi-square test ( $\left.\mathrm{n}, \%\right)$; $b$ Student's $t$ test (mean $\pm \mathrm{SD}$ ).

QT - Chemotherapy; V- Red light; IV - Infrared Light; TCTH - Stem-Hematopoietic Cell Transplantation; LLLT - Low Level Laser Therapy.

Patients submitted to HSCT at Walter Cantidio Hospital of Federal University of Ceará- Fortaleza-CE. 